\title{
Tempo e Patrimônio*
}

\section{Temporality and Patrimony ${ }^{\star \star}$}

\author{
FRANÇOIS HARTOG \\ École des Hautes Études en Sciences Sociales \\ 54 , boulevard Raspail, 75006 Paris \\ webmestre@ehess.fr
}

\begin{abstract}
RESUMO O artigo discute a redefinição da "memória" e do "patrimônio" dentro do novo "regime de historicidade" que o Ocidente vive após a Queda do Muro de Berlim (1989). Estas palavras-chave são tratadas como indícios, sintomas, de nossa relação com o tempo, como testemunhas da "crise" da ordem presente do tempo. O problema abordado: um novo regime de historicidade, centrado sobre o presente, estaria se formulando? Para o autor, ocorreu um crescimento rápido da categoria do presente e se impôs a evidência de um presente onipresente, que ele nomeia "presentismo", onde se vive entre a amnésia e a vontade de nada esquecer.
\end{abstract}

Palavras-chave memória, patrimônio, história

ABSTRACT This article discusses the redefinition of "memory" and "patrimony" within the new "regime of historicity" set in motion in the West after the fall of the Berlin Wall (1989). These keywords are treated as indicators or symptoms of our relation with time, as witnesses of the "crises" of the present order of time. The question that is approached is the following: is

* Artigo recebido em 04/08/2005. Autor convidado.

** Tradução: José Carlos Reis/Departamento de História/UFMG 
a new regime of historicity, one based on the present, taking shape? In the author's view, the category of present has grown rather fast and imposed an omnipotent present, which he names "presentism". This condition causes one to be torn between amnesia and the desire not to forget.

Key words Memory, Patrimony, Historicity

Historiador da história, entendida como uma forma da história intelectual, eu pouco a pouco fiz minha a constatação de Michel de Certeau, que lembrava, no final dos anos 1980, que "sem dúvida, a objetivação do passado, há três séculos, tinha feito do tempo o impensado de uma disciplina, que não cessava de utilizá-lo como um instrumento taxinômico". ${ }^{1}$ O tempo tornou-se tão habitual para o historiador, que ele o naturalizou ou instrumentalizou. Ele é impensado, não porque seria impensável, mas porque não o pensamos ou, mais simplesmente, não se pensa nele. Historiador atento ao meu tempo, eu, assim como muitos outros, observei o crescimento rápido da categoria do presente até que se impôs a evidência de um presente onipresente. É o que nomeio aqui "presentismo".

Poderíamos abordar melhor este fenômeno? Qual é o seu alcance? Que sentido atribuir-Ihe? Por exemplo, no quadro da história profissional francesa, a aparição de uma história se reivindicando, a partir dos anos 1980, como "história do tempo presente" acompanhou este movimento. Às demandas múltiplas da história contemporânea ou muito contemporânea, a profissão foi solicitada, algumas vezes intimada a responder. Presente em diferentes frentes, esta história se achou posta sob os projetores da atualidade judiciária, quando dos processos por crimes contra a humanidade, que têm por característica primeira de se haver com a temporalidade inédita do imprescritível.

Para conduzir esta pesquisa, a noção de "regime de historicidade" me pareceu operatória. Eu a tinha apresentado rapidamente uma primeira vez em 1983, para dar conta de um aspecto, o mais interessante, para mim, das proposições do antropólogo americano Marshall Sahlins, mas ela tinha naquele momento chamado pouco a atenção: a minha pouco mais do que a dos outros. ${ }^{2}$ Seria necessário outros tempos! Retomando as reflexões de Claude Lévi-Strauss sobre as sociedades "quentes" e as sociedades "frias", Sahlins procurava apreender a forma de história que tinha sido própria às

1 DE CERTEAU, Michel. Histoire et Psychanalyse entre science et ficition, Paris : Gallimard, 1987, p. 89. Voir Jean LEDUC. Les Historiens et le Temps. Conceptions, problematiques, ecritures. Paris : Ed. du Seuil, 1999.

2 HARTOG, François. "Marshall Sahlins et I' anthropologie de I' histoire". In: Annalles ESC, nº 6. Paris: EHESS, 1983, p. 1256-1263. 
ilhas do Pacífico. Tendo por assim dizer deixado a expressão de lado, sem a elaborar mais, eu a reencontrei, não mais nos povos autóctones do passado, mas no presente e aqui; mais exatamente, após 1989, ela se impôs quase dela mesma como uma das formas de interrogar uma conjuntura, onde a questão do tempo tornava-se uma questão forte, um problema: uma obsessão algumas vezes.

No intervalo, eu me familiarizei com as categorias meta-históricas da "experiência" e da "espera" (ou "expectativa"), tais como foram trabalhadas pelo historiador alemão Reinhart Koselleck, com vistas a elaborar uma semântica dos tempos históricos. Interrogando as experiências temporais da história, ele pesquisava "como em cada presente, as dimensões temporais do passado e do futuro tinham sido postas em relação". " É justamente aí que era interessante investigar, levando em conta as tensões existentes entre "campo de exercício" ("experiência" - NT) e "horizonte de espera" e estando atento aos modos de articulação do presente, do passado e do futuro. A noção de regime de historicidade podia assim se beneficiar de um diálogo entre (fosse por meu intermédio) de Sahlins com Koselleck: da antropologia com a história.

Um colóquio, concebido pelo helenista Marcel Detienne, comparatista convicto, foi a ocasião de retomá-la e trabalhá-la em comum com um antropólogo, Gérard Lenclud. Era uma forma de prosseguir, deslocando um pouco, o diálogo, intermitente, mas recorrente, menos intenso, algumas vezes, mas jamais abandonado, entre antropologia e história, que Claude Lévi-Strauss tinha aberto em 1949. "Regime de historicidade", escrevíamos então, podia se compreender de duas formas. Em uma acepção restrita, é como uma sociedade trata seu passado. Em uma acepção ampla, regime de historicidade serviria para designar "a modalidade de consciência de si de uma comunidade humana". Como, para retomar os termos de LéviStrauss, ela "reage" a um "grau de historicidade" idêntico para todas as sociedades. Mais precisamente, a noção devia poder fornecer um instrumento para comparar tipos de histórias diferentes, mas também e mesmo antes, eu acrescentaria agora, para iluminar modos de relação ao tempo: formas da experiência do tempo, aqui e lá, hoje e ontem. Maneiras de ser no tempo. Se, do lado da filosofia, a historicidade, da qual Paul Ricoeur traçou a trajetória de Hegel a Heidegger, designa "a condição de ser histórico", ${ }^{4}$ ou ainda "o homem presente a ele mesmo enquanto história", ${ }^{5}$ aqui, nós seremos mais atentos à diversidade dos regimes de historicidade.

KOSELLECK, Reinhart. Le futur passé. Paris : EHESS, 1990, p. 307-329.

RICOEUR, Paul. La Mémoire, I'histoire, I'oublie. Paris : Ed. du Seuil, 2000, p.480-498 e "Mémoire: approches historiennes, approche philosophique". In: Le Débat, no 122, 2002, p.42-44.

5 LYOTARD, Jean-François. "Les Indiens ne cueillent pas de fleurs". In: Annales ESC, n² 20, 1965, p. 65 (artigo sobre O Pensamento Selvagem, de Claude Lévi-Strauss). 
Enfim, ela me acompanhou quando de minha estada em Berlim, ao Wissenschaftskollelg, em 1994, quando os restos do Muro não tinham ainda desaparecido, o centro da cidade era um canteiro de obras, já em curso ou a fazer, e discutíamos já a reconstrução ou não do Castelo real, e as grandes fachadas arruinadas, metralhadas dos imóveis do Leste tornavam visível um tempo que, lá, tinha escoado de outra forma. Seria evidentemente falso dizer que ele tinha se congelado. Com seus grandes espaços vazios, baldios, e suas "sombras", Berlim me fazia o efeito de uma cidade para historiadores onde mais do que em outros lugares podia aflorar o impensado do tempo (não somente o esquecido, o reprimido, o renegado).

Mais do que qualquer outra cidade da Europa, do mundo, talvez, Berlim fez trabalhar, ao longo dos anos 1990, milhares de pessoas, dos aterros dos imigrantes aos grandes arquitetos internacionais. Boa notícia para os urbanistas e os jornalistas, ela se tornou um ponto de passagem obrigatório, até mesmo "da moda", um "bom tema", um laboratório, um lugar de "reflexão". Ela suscitou comentários inumeráveis e múltiplas controvérsias; ela levou à produção de massas de imagens, de palavras e de textos, provavelmente alguns grandes livros também. ${ }^{6}$ Sem esquecer os sofrimentos e as desilusões trazidas por estas mudanças bruscas. Pois, lá, mais ainda do que alhures, o tempo era um problema, visível, tangível, ineludível. Que relações manter com o passado, os passados, é claro, mas também, e fortemente, com o futuro? Sem esquecer o presente ou, inversamente, correndo o risco de ver somente a ele: como, no sentido próprio do termo, o habitar? Que destruir, que conservar, que reconstruir, que construir e como? São decisões e ações que impõem uma relação explícita ao tempo. Quem se cega a tal ponto que não consegue vê-lo?

De um lado e do outro de um muro, que iria pouco a pouco tornar-se um muro de tempo, procurou-se primeiro apagar o passado. Declarar, como Hans Scharoun: "não se pode ao mesmo tempo construir uma sociedade nova e reconstruir os prédios antigos", podia valer para os dois lados. ${ }^{7}$ Arquiteto famoso, Scharoun, que tinha presidido a comissão de urbanismo e de arquitetura logo após a guerra, construiu especialmente o auditório da Filarmônica. Cidade emblemática, lugar de memória, para uma Europa tomada em seu conjunto, para dizer pouco, entre a amnésia e o dever de memória, tal é Berlim à aurora do século XXI. Lá, aos olhos do historiador que vagueia (flâneur) se dão ainda a ver fragmentos, restos, marcas de ordem do tempo diferentes, como se fala de ordens em arquitetura.

6 Por exemplo, GRASS, Günter. Toute une Histoire. Paris : Seuil, 1997; NOOTEBOOM, Cees. Le Jour des morts. Arles: Actes Sud, 2001

7 FRANÇOIS, Etienne. "Reconstruction allemande" In: Patrimoine et passions identitaires, sob a presidência de Jacques Le Goff. Paris : Fayard, 1998, p.313 (para a citação de Scharoun) e Gabi Dolff-Bonekämper, "Les monuments de I' histoire contemporaine a Berlin: ruptures, contradictions et cicatrices" In: L 'Abus monumental, sob a presidencia de Régis Debray. Paris : Fayard, 1999, p. 363-370. 
Assim, formada sobre as margens das ilhas do Grande Pacífico, a noção chegou a Berlim, ao centro da história européia moderna.

Nós interrogamos, aqui, o nosso contemporâneo a partir destas duas palavras mestras que são a memória e o patrimônio. Muito solicitadas, abundantemente comentadas e declinadas de múltiplas formas, estas palavras-chave não serão mais desdobradas, aqui, por elas mesmas, mas tratadas unicamente como indícios, sintomas também de nossa relação com o tempo - formas diversas de traduzir, refratar, seguir, contrariar a ordem do tempo: como testemunham as incertezas ou uma "crise" da ordem presente do tempo. Uma questão nos acompanhará: um novo regime de historicidade, centrado sobre o presente, estaria se formulando?

O que significou, do ponto de vista do tempo, de sua ordem, o movimento de extensão e de universalização do patrimônio, ao qual nós temos assistido há um bom quarto de século? De qual regime de historicidade a patrimonialização galopante dos anos 1990, como nós a qualificamos algumas vezes, pode ser a marca? Este gosto pelo passado vinha testemunhar repentinamente um tipo de nostalgia por um antigo regime de historicidade, contudo, desde há muito fora de uso? Inversamente, como ele podia ainda se ajustar a um regime moderno, que tinha posto, há dois séculos, todo seu "fervor de esperança" no futuro?

No curso do período, o patrimônio se impôs como a categoria dominante, englobante, senão devorante, em todo caso, evidente, da vida cultural e das políticas públicas. Nós já recenseamos todos os tipos de "novos patrimônios" e declinamos "novos usos" do patrimônio. Na França, desde 1983, as Jornadas do Patrimônio atraíram cada vez mais visitantes aos imóveis ditos do Patrimônio: mais de onze milhões em setembro de 2002. Estes resultados, devidamente estabelecidos e proclamados a cada ano pela mídia, são como um recorde a bater no ano seguinte. As Jornadas do Patrimônio têm se disseminado por todo o mundo e fala-se hoje, sobretudo através das iniciativas e das convenções da UNESCO, de universalização do patrimônio, enquanto que, a cada ano, se alonga a lista dos sítios do patrimônio universal da humanidade. ${ }^{8}$ Uma Escola Nacional do Patrimônio, encarregada de formar os futuros conservadores, funciona desde 1991, em Paris. Existe, desde 1996, uma Fundação do Patrimônio. Inspirada, em suas expectativas pelo menos, no National Trust britânico, ela se mostrou muito discreta, na verdade. Enfim, Entretiens du Patrimoine (Discussões sobre o

8 Consulta no website do Centre du Patrimoine mondial, ele recenceava 730 ao fim de 2002 
Patrimônio) são organizadas desde 1984 pela Direção do patrimônio no Ministério da Cultura. Discute-se tudo o que toca o patrimônio, inclusive, ultimamente, os seus "abusos". ${ }^{9}$

Os "Lugares de Memória" do historiador Pierre Nora chegaram ao diagnóstico de uma "patrimonialização" da história da França, senão da França mesma, na medida em que a mudança de um regime de memória a outro nos fazia sair da "história-memória" para entrar em uma "históriapatrimônio". Notável em relação a isto é a definição dada na lei de 1993 sobre o patrimônio monumental: "nosso patrimônio é a memória de nossa história e o símbolo de nossa identidade nacional". Passando para o lado da memória, ele se torna memória da história e como tal símbolo de identidade. Memória, patrimônio, história, identidade, nação se encontram reunidos na evidência do estilo direto do legislador.

Nesta nova configuração, o patrimônio se encontra ligado ao território e à memória, que operam um e outro como vetores da identidade: a palavrachave dos anos 1980. Mas, trata-se menos de uma identidade evidente e segura dela mesma do que de uma identidade que se confessa inquieta, arriscando-se de se apagar ou já amplamente esquecida, obliterada, reprimida: de uma identidade em busca dela mesma, a exumar, a "bricoler", e mesmo a inventar. Nesta acepção, o patrimônio define menos o que se possui, o que se tem e se circunscreve mais ao que somos, sem sabê-lo, ou mesmo sem ter podido saber. O patrimônio se apresenta então como um convite à anamnese coletiva. Ao "dever" da memória, com a sua recente tradução pública, o remorso, se teria acrescentado alguma coisa como a "ardente obrigação" do patrimônio, com suas exigências de conservação, de reabilitação e de comemoração.

Fora do mundo cristão, o caso do Japão sempre chamou a atenção. 0 fato de que o país se dotou, bem rápido, após a restauração de Meiji (1868), de uma legislação de proteção das obras arquiteturais e artísticas antigas, permitia apreender, mais facilmente do que alhures, as semelhanças e as diferenças com relação ao conceito europeu de patrimônio. ${ }^{10}$ Uma primeira Diretiva de inventário de 1871 é seguida, em 1897, de uma lei sobre a preservação dos antigos santuários e templos onde é introduzida a noção de "tesouro nacional". A palavra "tesouro" indica que o objeto tira seu valor de

9 L'abus monumental, sob a presidência de Régis Debray, Paris, Fayard, 1999, en particulier, R. Debray « Le monument ou la transmission comme tragédie ", p. 11-32. Il y avait eu déjà Tzvetan Todorov, Les abus de la mémoire, Paris, Arléa, 1995.

10 BOURDIER, Marc. «Le mythe et l'industrie ou la protection du patrimoine culturel au Japon », Genèses, 11, 1993, p. $82-110$ 
seu pano de fundo imaterial (sua origem divina, por exemplo)..${ }^{11}$ Interessa-se, então, pelo patrimônio religioso (xintoísta), sobretudo. Depois, em 1919, vem se acrescentar a lei sobre a preservação dos sítios históricos, pitorescos e dos monumentos naturais. Enfim, a lei de 1950 sobre a proteção dos bens culturais dá lugar, pela primeira vez, ao "patrimônio cultural intangível". Deste conjunto legislativo e das práticas patrimoniais que ele codifica, nós reteremos duas particularidades somente.

Está prevista a reconstrução periódica de certos edifícios religiosos. 0 fato de que eles são edificados em madeira não explica tudo, pois a reconstrução é idêntica e se faz segundo um calendário fixado antecipadamente. É em particular o caso do grande santuário d 'Ise. O templo da deusa Amaterasu, ancestral mítica da casa imperial, é reconstruída de forma idêntica em madeira de cipreste do Japão a cada 20 anos. Instaurada no século VII, o rito continuou até hoje (sem dúvida, com períodos de interrupção). A próxima reconstrução está prevista para 2013. Conta sobretudo a permanência da forma. O dilema ocidental "conservar ou restaurar" não existe. ${ }^{12}$ Em compensação, um japonês que visita Paris será (mais exatamente teria sido outrora) chocado pelo esforço desenvolvido para conservar os objetos e os monumentos históricos contra o desgaste do tempo. ${ }^{13}$ De fato, a política cultural japonesa não tinha por primeira preocupação nem a visibilidade dos objetos nem a manutenção desta visibilidade. Ela repousava sobre uma outra lógica que era a da atualização.

É o que permite compreender melhor a designação "tesouro nacional vivo", tal como foi especificada na lei de 1950. Esta designação é conferida a um artista ou artesão, não como pessoas, mas somente enquanto ele é "detentor de um importante patrimônio cultural intangível". O título, que pode recompensar um indivíduo ou um grupo, obriga o eleito a transmitir o seu saber. Ele recebe, para isso, indenizações. Desta disposição original fica claro que o objeto ou sua conservação conta menos do que a atualização de um savoir-faire, que se transmite ao se atualizar. Como o templo de madeira, a arte tradicional existe na medida em que ela está no ou dentro do presente. Decorre daí que estas noções, tão centrais na constituição do patrimônio do ocidente, de "original", de "cópia", de "autenticidade", não existem ou não são, em todo caso, portadoras dos mesmos valores no Japão. Seguramente, o passado contava, mas a ordem do tempo operava de outra forma que na Europa. De um tempo que não era linear, derivava uma

11 FIÉVÉ, Nicolas. «Architecture et patrimoine au Japon : les mots du monument historique ", L'abus monumental, op. cit., Paris, Fayard, 1999, p. 333.

12 É o título de um texto do arquiteto italiano Camillo Boito, publicado em 1893, onde ele tenta definir uma posição intermediária entre a representada por Viollet-le-Duc — « restaurar um edifício não é conservá-lo, consertá-lo ou refazê-lo, mas restabelecê-lo de uma forma tão completa que pode não ter existido em monento algum » (Dictionnaire de l'architecture) — e a representada por Ruskin — « conservar absolutamente, até a ruinificação se for preciso »-, ver Leniaud, op. cit. p. 186-188.

13 OGINO, Masahiro. "La logique d'actualisation. Le patrimoine au Japon", Ethnologie française, XXV, 1995, p.57-63. 
outra figuração da permanência e uma outra relação com o vestígio. Isto é só um esquema rápido, um simples esboço de um olhar afastado, mas é suficiente para desfazer a evidência do conceito europeu de patrimônio.

No decorrer destes anos, a vaga patrimonial, em sintonia com a da memória, portanto, tomou cada vez mais amplitude até tender para este limite que seria o "tudo patrimônio". Assim como se anuncia ou se reclama memórias de tudo, assim tudo seria patrimônio ou suscetível de tornar-se. A mesma inflação parece reinar. A patrimonialização ou a musealização se aproximando sempre mais do presente, foi preciso estipular, por exemplo, "que nenhuma obra de arquiteto vivo seria legalmente considerada como monumento histórico". ${ }^{14}$ Isto é um indício muito claro deste presente que se historiciza, já evocado.

Uma manifestação urbana da incidência do tema do patrimônio e destes jogos do tempo se observou nas políticas de reabilitação, renovação, revitalização dos centros urbanos. Deseja-se museificar, mas mantendo vivo, ou melhor, revitalizar reabilitando. Ter um museu, mas sem o fechamento do museu: aqui ainda, um museu "fora dos muros"? Um museu propriamente de sociedade, senão um museu social. É claro, este projeto implicava, ultrapassando a noção de monumento histórico, a tomada de consciência de que a proteção do patrimônio devia se conceber como um projeto urbano de conjunto. O que exigiu a passagem da Carta de Atenas, em 1931, à de Veneza, em 1964. ${ }^{15}$ Donde este outro paradoxo, hoje, o mais autenticamente moderno seria o passado histórico, mas posto sob as normas modernas. No limite, conservamos apenas as fachadas.

E quando este passado faltava, contribuindo para o mal-estar das periferias ou das cidades-dormitórios, fizeram-no aparecer. Produziu-se lugares de patrimônio urbano para construir a identidade escolhendo uma história, que se torna a história, a da cidade ou do bairro: história inventada, reinventada ou exumada, depois mostrada, em torno da qual se organiza, em todos os sentidos da palavra, a "circulação".

Os patrimônios se multiplicam. Assim, um exemplo entre outros, a lei relativa à Fundação do Patrimônio, preocupada em nada omitir, repertoriou o "patrimônio cultural protegido", o "patrimônio cultural de proximidade" (este "tecido conjuntivo" do território nacional), o "patrimônio natural" (que compreende a "noção de paisagens"), o "patrimônio vivo" (as raças animais e espécies vegetais), o "patrimônio imaterial" (com os savoir-faire tradicionais, as tradições populares, o folclore). O patrimônio genético já

$14 \mathrm{CHOAY}$, Françoise. Avant-propos à Alois Riegl, op. cit. p. 9

15 A conferência de Atenas foi convocada por iniciativa da Comissão Internacional para a Cooperação Intelectual da SDN e do Conselho Internacional dos Museus, voir infra $\mathrm{p}$ 
freqüenta a mídia e o patrimônio ético começa a entrar. O ritmo acelerado da constituição, e mesmo da produção do patrimônio, um pouco por todo lado no mundo, é uma constatação que cada um pôde fazer. Uma série de cartas internacionais veio assegurar, coordenar e dar forma a este movimento. Mesmo se já existem há muito tempo princípios a seu respeito.

A primeira, a Carta de Atenas para a Restauração dos Monumentos históricos, se centrava somente sobre os grandes monumentos e ignorava o resto. Trinta anos mais tarde, a Carta de Veneza ampliava consideravelmente os objetivos, pois pretendia levar em conta "a Conservação e a Restauração dos Monumentos e dos Lugares". O artigo $1^{\circ}$ dá uma definição muito mais extensa do monumento histórico: "a noção de monumento histórico inclui a criação arquitetural isolada assim como o sítio urbano ou rural que traz o testemunho de uma civilização particular, de uma evolução significativa ou de um evento histórico. Ele se estende não somente às grandes criações, mas também às obras modestas que adquiriram com o tempo uma significação cultural". O preâmbulo acentua fortemente a preservação e introduz a noção de patrimônio comum da humanidade. "A Humanidade, que toma consciência a cada dia da unidade dos valores humanos, considera [as obras monumentais dos povos] como um patrimônio comum, e, face às gerações futuras, se reconhece solidariamente responsável pela sua preservação. Ela se obriga a transmiti-los em toda a riqueza de sua autenticidade". O patrimônio é constituído de testemunhos, grandes ou pequenos. Como em relação a todo testemunho, nossa responsabilidade é de saber reconhecê-los em sua autenticidade, mas além disso nossa responsabilidade se encontra engajada em relação às gerações futuras.

Nesta tomada de consciência, o resgate dos templos de Abou-Simbel, em 1959, quando da construção da grande barragem de Assouan teve um papel importante. Foi uma enorme experiência, muito midiatizada, de sensibilização das opiniões públicas. E, maravilha, o passado distante e as técnicas modernas pareciam se aliar: o futuro não se instalava sobre as ruínas do passado. Ele lhe dava, ao contrário, a oportunidade de permanecer visível no futuro, um tipo de semióforo duplicado. O discurso pronunciado por André Malraux por ocasião desta campanha o testemunha magnificamente: "seu apelo pertence à história do espírito não porque é preciso salvar os templos de Nubie, mas porque com ele a primeira civilização mundial reivindica publicamente a arte mundial como sua herança indivisível".

Quanto mais o patrimônio (a noção pelo menos) crescia, mais enfraquecia o monumento histórico (a categoria). A lei de 1913 tinha substituído o "interesse nacional" como único critério de classificação de um monumento, [pelo] "o interesse público do ponto de vista da história e da arte". O que representava já um alargamento do campo da noção. Mas, hoje, o privilégio da definição da história-memória nacional tem a concorrência ou é contestado em nome de memórias parciais, setoriais, particulares (de grupos, 
associações, empresas, coletividades, etc.), que querem se fazer reconhecer como legítimas, tão legítimas, até mesmo mais legítimas. O Estado-nação não impõe mais os seus valores, mas preserva mais rápido o que, no presente, imediatamente, mesmo na urgência, é tido como "patrimônio" pelos diversos atores sociais. ${ }^{16} \mathrm{O}$ próprio monumento tende a ser suplantado pelo memorial: menos monumento do que lugar de memória, onde se esforça para fazer viver a memória, a mantê-la viva e a transmiti-la.

De 1980 a 2000, recenseou-se na França 2241 associações, cujo objeto declarado é o patrimônio ou o habitat (cadre de vie): o "pequeno patrimônio”. Em sua maioria, estas associações são jovens, nascidas após 1980. Dando-se algumas vezes definições muito extensivas do patrimônio, que não se ajustam necessariamente com as categorias oficiais da administração ocupada pelo "grande patrimônio", elas tendem a desestabilizar a máquina administrativa de classificar. Pois, para elas, o valor dos objetos que elas elegeram reside, parcialmente, no fato de que estão elas mesmas na origem do seu reconhecimento. ${ }^{17}$ Trata-se, em suma, mais de patrimônio local, associando memória e território e de operações visando a produzir território e continuidade para aqueles que lá habitam, hoje. "As associações do patrimônio mostram a construção de uma memória que não é dada, portanto, não perdida. Elas abrem à constituição de um universo simbólico. Também o patrimônio não deve ser visto a partir do passado, mas a partir do presente, como categoria de ação do presente e sobre o presente". ${ }^{18}$ Enfim, o patrimônio, ao tornar-se um ramo principal da indústria do turismo, é objeto de investimentos econômicos importantes. Sua "valorização" se insere, então, diretamente, nos ritmos e temporalidades rápidas da economia de mercado de hoje, chocando-se e aproximando-se dela.

O século XX é o que mais invocou o futuro, o que mais construiu e massacrou em seu nome, o que levou mais longe a produção de uma história escrita do ponto de vista do futuro, conforme aos postulados do regime moderno de historicidade. Mas, ele é também o século que, sobretudo no seu último terço, deu extensão maior à categoria do presente: um presente massivo, invasor, onipresente, que não tem outro horizonte além dele mesmo, fabricando cotidianamente o passado e o futuro do qual ele tem necessidade. Um presente já passado antes de ter completamente chegado. Mas, desde o fim dos anos 1960, este presente se descobriu inquieto, em busca de raízes, obcecado com a memória. À confiança no progresso se

16 O número de edifícios protegidos passou de 24000 em 1960 a 44709 em 1996.

17 GLEVAREC, Hervé et SAEZ, Guy, Le patrimoine saisi par les associations, op. cit. p. 129-193.

18 Ibid. p. 263 
substituiu a preocupação de guardar e preservar: preservar o quê e quem? Este mundo, o nosso, as gerações futuras, nós mesmos.

Daí vem este olhar museológico lançado sobre o que nos cerca. Nós gostaríamos de preparar, a partir de hoje, o museu de amanhã e reunir os arquivos de hoje como se fosse já ontem, tomados que estamos entre a amnésia e a vontade de nada esquecer. Para quem? Para nós, já. A destruição do Muro de Berlim, seguida da sua museificação instantânea foi um bom exemplo, com a sua imediata mercantilização. Foram postas à venda imediatamente amostras devidamente marcadas com o selo Original Berlin Mauer. Se o patrimônio é doravante o que define o que nós somos hoje, o movimento de patrimonialização, este imperativo, tomado ele mesmo na aura do dever da memória permanecerá um traço distintivo do momento que nós vivemos ou acabamos de viver: uma certa relação ao presente e uma manifestação do presentismo.

No exame da trajetória do patrimônio, há um componente do qual nós não ainda conhecemos todo o alcance: a patrimonialização do meio ambiente. A UNESCO forneceu um bom começo, pois ela é ao mesmo tempo uma possante caixa de ressonância e um vasto laboratório mundial onde se elabora uma doutrina e se proclama os seus princípios. Em 1972, a Conferência geral adotou a "Convenção para a Proteção do Patrimônio Mundial Cultural e Natural". O texto parece não deixar nada fora de sua perspectiva: o patrimônio mundial, ele é cultural e natural. Por que uma Convenção internacional? Porque, o preâmbulo parte desta constatação, o patrimônio universal é cada vez mais ameaçado de destruição "não somente pelas causas tradicionais de degradação, mas ainda pela evolução da vida social e econômica que os agrava por fenômenos de alteração ou de destruição ainda mais temíveis". Estas considerações conduzem também à introdução de uma noção nova: a de proteção, que incumbe a toda a coletividade internacional.

Hoje, a UNESCO desejaria reunir a consideração da diversidade cultural, a preocupação com a biodiversidade e os esforços com vistas ao desenvolvimento durável. ${ }^{19} \mathrm{O}$ que reúne estes três conceitos e estes três objetivos é a preocupação ou o imperativo da proteção, ou melhor, da preservação. Trata-se de proteger o presente ou de preservar o futuro? Trata-se dos dois, é evidente. A questão não é, no entanto, necessariamente ociosa. Raciocinamos indo do futuro ao presente ou do presente em direção ao futuro? Nós voltaremos a este ponto.

19 MATSUURA, Koïchiro. "Eloge du patrimoine culturel immatériel », Le Monde, 11 septembre 2002. 
Do ponto de vista da relação ao tempo, de que esta proliferação patrimonial é sinal?

Ela é sinal de ruptura, seguramente, entre um presente e um passado, o sentimento vivido da aceleração sendo uma forma de fazer a experiência: a mudança brusca de um regime de memória para um outro, do qual Pierre Nora fez o ponto de partida de sua interrogação. O percurso da noção mostrou indubitavelmente que o patrimônio jamais se nutriu da continuidade, mas, ao contrário, de cortes e da problematização da ordem do tempo, com todos os jogos de ausência e presença, do visível e do invisível, que marcaram e guiaram as incessantes e sempre mutantes formas de produzir semióforos. Começando pela intrusão deste ausente inaugural que foi Jesus naquilo que se tornou, há muito tempo e por muito tempo, a tradição ocidental, com a imposição de uma nova ordem do tempo.

O patrimônio é uma maneira de viver as rupturas, de reconhecê-las e reduzi-las, referindo-se a elas, elegendo-as, produzindo semióforos. Inscrito na longa duração da história ocidental, a noção conheceu diversos estados, sempre correlatos com tempos fortes de questionamentos da ordem do tempo. O patrimônio é um recurso para o tempo de crise. Se há assim momentos do patrimônio, seria ilusório nos fixarmos sobre uma acepção única do termo.

Após as catástrofes do século XX, as numerosas rupturas, as fortes acelerações tão perceptíveis na experiência do tempo vivido, nem o surgimento da memória nem o do patrimônio são surpreendentes. A questão poderia ser: por que foi preciso esperar tanto tempo? Seguramente, porque a ordem do mundo e do tempo as tornava pouco possíveis. Foi necessária a reunião de toda uma série de condições, lembradas na abertura desta travessia pelo tempo. Em compensação, o que distingue o crescimento patrimonial contemporâneo dos precedentes é a rapidez de sua extensão, a multiplicidade de suas manifestações e seu caráter fortemente presentista, quando o presente tomou uma extensão inédita. O memorial é preferido ao monumento ou este último torna-se memorial, o passado atrai mais que a história; a presença do passado, a evocação e a emoção predominam sobre a tomada de distância e a mediação; enfim, este patrimônio é ele mesmo trabalhado pela aceleração: é preciso fazer rápido antes que seja muito tarde, antes que a noite caia e o hoje tenha desaparecido completamente.

Que ela se manifeste como demanda, se afirme como dever ou se reivindique como direito, a memória vale, no mesmo movimento, como uma resposta ao presentismo e como um sintoma deste último. Assim é também para o patrimônio. Mas, com alguma coisa a mais do ponto de vista da experiência e, finalmente, da ordem do tempo. A patrimonialização do meio ambiente, que designa a extensão provavelmente a mais massiva e a mais nova da noção, abre indubitavelmente sobre o futuro ou sobre novas interações entre presente e futuro. Não saímos, então, do círculo do 
presente, pois a preocupação com o futuro se apresenta mesmo como a razão de ser deste fenômeno? Salvo que este futuro não é mais promessa ou "princípio de esperança", mas ameaça. Tal é a reviravolta. Uma ameaça da qual nós fomos os iniciadores e da qual nós devemos nos reconhecer, hoje, na falta já de ontem, como os responsáveis.

Assim, interrogar o patrimônio e seus regimes de temporalidades nos conduziu, de maneira inesperada, do passado ao futuro, mas um futuro que não é mais a conquistar ou a realizar sem hesitar e, se preciso for, violentando o presente. Este futuro não é mais um horizonte luminoso para o qual marchamos, mas uma linha de sombra que colocamos em movimento em direção a nós, enquanto parecemos marcar passo no presente e ruminar um passado que não passa. 